Chàpter 34

\title{
THE DUTCH PROGRAM OF INVESTIGATIONS ON STORM SURGES IN THE NORTH SEA
}

\author{
J. B. Schijf \\ Rijkswaterstaat, The Hague, Netherlands
}

\section{Introduction.}

The North sea is a shallow sea and therefore it is very sensitive to windeffects. As a result the waterlevels along the coasts are, in addition to the tidal oscillations subject to a considerable wind setup and exceptionally severe gales throughout history have been accompanied by inundations of the low-lying regions bordering the North Sea, in particular its southern part.

No stretch of coast has suffered more than that belonging to the Netherlands and the adjacent parts of Belgium and North Western Germany. Several factors combine to bestow on us this doubtful privilege.

Firstly the most violent gales are predominantly from the North West, piling up the waters into the South Eastern corner.

Secondly the Netherlands, as the name implies, are among the lowest regions to be found on the sea coast, slightly more than half of the country lying below mean high water and one third even below mean sealevel.

Thirdly our coast is indented by a number of estuaries, enabling the sea to penetrate deeply into the country.

It is not surprising that after the establishment off regular observations both of sealevels and of meteorological data (say around half of the last century) the relations between wind and sealevels became an object of interest. For a thorough analysis of the dynamics of the North Sea the time had not yet come till recently.

When in the 20 s the project for the enclosure of the Zuyderzee was maturing, for the first time a quantitative analysis was undertaken of the dynamics of tides and storm surges in the Zuyderzee and its immediate surroundings. Later similar studies have been made with regard to the estuaries in the South Western Netherlands. It has been possible to arrive at a complete understanding and also at a quantitative treatment to a high standard of accuracy of the behaviour of the tides and storm surges in these areas. In these calculations the waterlevels in the North Sea itself were considered to be unaffected and taken as boundary conditions.

In later years the problems of the dynamics of storm surges in the North Sea has been attacked both by British (Coldsbrough, Doodson, Proudman, Corkan) and Dutch scientists. On the Dutch side this was mainiy the work of the Oceanographic Section of the Royal Netherlands Meteorological Institute and its results for the time being have been cristallized in the doctors thesis of Schalkwijk (1947). The main practical value has been to provide a useful basis for fairly accurate short term predictions of waterlevels based on the meteorological forecasts.

On the other hand also studies of a statistical nature on the occurrence of high and very high sealevels have been going on for some time, mainly by the Research Divisions of the Rijkswaterstaat. Their purpose was to provide rational design data for seawalls and similar constructions.

Progress along these Iines was relatively slow; as the problem is not an easy one and it has many ramifications. The people working at it were not many and they ha? other interests besides. There was no reason to treat the subject with any special urgency. 

IN THE NORTH SEA

During the night of 31 January to 1 February 1953 all this has been changed. The vital urgency of these matters was brought home to us very forcibly.

Since then, as soon as the immediate demands of the repair and reconstruction of the dikes had been satisfied, the attack of the storm surge problems has been resumed in full force. A special Government committee, the Delta-Committee, has been appointed to advise the Government on the general policy with regard to the danger from the North Sea, more in particular on the primary. choice between either a big scale program of closing off of estuaries or a radical raising and strengthening of several thousands of $\mathrm{kms}$ dike. Under the sponsorship of this Committee a collaboration has been set up between the Research Divisions of the Rijkswaterstaat, the Meteorological and Oceanographical Sections of the Royal Dutch Met. Inst. and the Mathematical Centre. In the last mentioned organisation a group of prominent mathematicians are united for the purpose of developing and applying mathematical methods for technical, commercial and social problems. Its equipment includes an electronic computer.

\section{The statistical problem.}

In the old-time practice of seawall construction the highest known water level was taken as a design criterium. The realisation that the height of sea levels should be treated as a statistical problem dates back only a short time and it is still regarded in same circles as a rather suspect novelty.

The earliest and most thoroughly investigated set of data in the Netherlands are the recorded high water levels at Hook of Holland. It has been found that, plotted on a semi-logarithmic diagram, they yield a straight frequency curve. Now a straight line rather invitingly suggests a straight line extrapolation but, on the other hand, it does by no means offer a scientific justification for doing so. In fact it might be, and is, argued that an extrapolation from a 60-year series of records into frequencies dealing with much longer periods has no real basis whatever. Still, unless we are content with waiting for another 1000 years before being ready to fix reasonably safe design data for our seawalls, we have to decide on some manner of extrapolation. This situation calls for an investigation into the problem, as searching as the present state of the science of mathematical statistics allows.

In the course of this investigations a number of questions have been or are being looked into, not only with regard to the Hook of Holland data, but also those from other stations along the coast. It should be mentioned that not all the other series conform to the straightine frequency relation. A main question from which most other follow is if the data represent a homogeneous statistical material.

A high water level results from the combined action of the astronomical tide and the meteorological effects; should they be separated and treated one apart from the other? A rather simple way of separating consists of subtracting the predicted HWlevel from the recorded level, although this procedure is not entirely sound, because the interaction of tide and meteorological effect cannot be treated as a simple superposition. However when the process is carried out, it does not materially alter the statistical position. 
As a more or less defined meteorological situation, such as a depression, generally has a longer duration than one tidal cycle, successive HWlevels are not statistically independent. There is a certain measure of persistence, which can be eliminated by classifying the recorded levels after depressions and selecting the maximum HWlevels associated with individual depressions.

Proceeding further along this line it appeared worth while to consider in particular depressions of a type associated with storm surges. This has the disadvantage that less data are available, but the probable advantage of providing more homogeneous matter.

Another step along the same general line of thought is to consider the winter semester separately, and again the three months of most frequent gales - November, December, January - separately.

Proceeding yet further it has been tried to ascertain whether certain years or groups of years show a greater tendency than normal to produce storm surges (dangerous years), also if any correlation can be found between frequency of storm surges and sun spot activity.

The philosophy behind these converging selections is to find out if possible if the very high waterlevels show a significantly different law of frequency distribution from the entire mass of data.

From the trend of the questions it will be clear tha: the in-. vestigation is not confined to a study in mathematical statistics pure and simple, but all along the line physical and meteorological relationshipsare drawn in. Of course this calls for a close coopperation between the teams of statisticians, meteorologists, oceanographers and hydraulicians busy on the different aspects of the problem, for which purpose frequent gatherings of greater or smaller groups are organized.

Although the statistical investigations are still in full swing, certain preliminary results have already emerged. Neither for sun spot activity, nor for a classification in groups of more and less dangerous years a statistically significant indication has been found. on the other hand the classification after depressions appears to be decidedly useful.

So far it has not been found at least for Hook of Holland that a straight line extrapolation of the frequency diagram should be condemned.

Each selected group of data very faithfully shows a straight line relation. However, there appears a tendency for selected groups of HWlevels to follow a frequency curve with a different gradient from the overall curve, in such a way as to increase the probability of rery high levels. This is felt to require very careful attention as there appears to be a strong argument in favour of an extrapolation being based predominantly on the tendency of that section of the data which may be estimated to be most representative for physical patterns, associated with severe storm surges.

Still, the investigation is by no means completed and moreover no statistical findings can realy be conclusive as long as the dynamical studies have not produced sufficient evidence to support them.

\section{Nature of the dynamic problem.}

Quite a number of studies have been made in several countries on the equilibrium setup of an enclosed body of water under the action of a steady and homogeneous wind field. Although not all the factors relevant to that problem have been made entirely clear, a suficient working knowledge for practical purposes has been gathered. 


\section{THE DUTCH PROGRAM OF INVESTIGATIONS ON STORM SURGES 475 IN THE NORTH SEA}

One of the sarly findings, both from the theoretical and the empirical point of view, has been that the setup is inversely proportional to the depth of water, or nearly so. This explains readily the considerable setup values experienced in the relatively shallow North Sea. The fact that the depth in the North sea is not homogeneous and that its shape is not regular, complicates the problem somewhat, but does not in itself present real difficulties. If it were only for this, we would still have a fairly simple problem.

Apart from that however, the North Sea departs in several respects from the idealized setup case. It is by no means an enclosed body of water, being open to the Atlantic in the North, and having a second connection via the Channel in the South. Another connection though oI less importance, exists with the Baltic in the East. Also the wind field is neither homogeneous nor steady. Lastly it is not only the wind action we have to deal with, but also the tidal motion and because of the non-linear character of some of the relevant terms, in particular the bed friction, the two motions cannot be superposed in a simple way. Not only that, but the simultaneous action of gradient and Coriolis forces throughout the depth and wind shear on the surface give rise to distorted velocity distribution curves, thus complicating the relation between mean velocity and friction.

The problem confronting us therefore is cynamic in nature, bearing on an irregularly shaped sea, with varying depths and several open boundaries, driven by the tide and by a complicated and varying windpattern, large enough for Coriolis forces to have an appreciable effect and shallow enough for the bed friction to be counted with.

\section{Dissection of the dynamic problem.}

As a first stage in an endeavour to deal with our problem in its full complexity, it seems indicated to try to dissect it as far as possible in its component parts. We may at least expect to gain a certain amount of insight into the significance of the individual factors and subiactors and it is not unreasonable to hope that after mastering more or less simplified models of the true dynamic.pattern we may see our way to a sufficiently close approach to the complete problem.

We may be guided by the experience that has been accumulated. in the calculations of tides and storm surges in our estuaries. This problem is simpler than the North Sea problem because of several reasons.

1. The channels are narrow enough to allow for neglecting the flow and its derivatives in the widthdirection of the channel. So the problem can be stated in $x, z$ en $t$ instead of $x, y, z$ en $t$.

2. This implies that Coriolis forces need not be taken into account.

3. The wind-action on the estuaries themselves is not very important. It can be introduced as a correcticn term.

4. In those shallow waters the ratio of inertia to friction is small enough as a rule not to have an appreciable influence on the vertical velocity distribution. Hence an integration with regard to $z$ is possible, leading to a direct relation between mean velocity and friction as expressed by the cheryy-formula. Then the problem is reduced to solving equations in $x$ and $t$ as independent variables.

on these lines the chunnel-theory as used in estuaries and similar waters has been developped. 
In the North Sea problem it is clear that limitation to unidirectional flow forms a rather crude schematization, which can only be useful for a rough exploration. It will also be unavoidable to include the windshearterm in the equation of motion.

As the only possibility of simplifying the basic equations remains the integration with respect to $z$. This requires a fundamental study of the vertical distribution of velocity and shear in a flow subject to the combined action of gradient forces, Coriolis forces and surface shear.

This study has been undertaken and it has led to a workable result, which boils down to the introduction of a modified Chézy-relation with correction terms depending from the ratio of the vector velocities of wind and water.

A number of separate problems; which are suitable to probe into the characteristic features of the relevant factors can be selected. They are:

1. The windeffect of a homogeneous and stationnary windfield, a. on a basin of regular shape and constant depth

b. on a basin of regular shape and a depth variable from place to place

c. on a basin of irregular shape and constant depth

d. on a basin of irregular shape and variable depth.

2. The windeffect of an inhomogeneous, but stationnary windfield on $a-b-c$ and $d$.

3. The windeffect of a homogeneous windfield, varying in intensity on $a-b-c$ and $d$.

4. The windeffect of an inhomogeneous moving windfield on $a-b-c$ and d.

This group of problems is directed to the understanding of the behaviour of the North Sea as a whole. For this purpose its shape may be schematized into a rectangular basin open to the Atlantic at the Northern end and continued with a converging trapezoidal basin in the South, which in turn is connected with a diverging trapezoidal basin (the Channel), open to the Atlantic.

The connection with the Baltic, which may be considered as having but a secundary importance, may be left out entirely in the first stage and possibly be introduced later as a correction.

The windpatterns to be investigated have to be selected on the basis of a study of the meteorological conditions associated with severe storm surges, which is carried out by the meteorologists.

As regards mathematical procedure it is indicated in the first place to lookfor a not too laborious approximation, enabling to obtain comparative results with a moderate amount of labour. This appears to be possible by linearizing the friction term on the same lines as in the harmonic method of tidal calculation used in estuaries and at the same time drop terms of secundary order.

Concerning the method of integration of the equations thus simplified there is as yet no definite choice of method. Several processes of iteration are tentatively used. Also a study on the suitabiity of a calculation based on characteristics is in progress as well as an investigation into the possibility of adapting the use of finite differinces to the electronic computer. 


\section{THE DUTCH PROGRAM OF INVESTIGATIONS ON STORM SURGES IN THE NORTH SEA}

It is hoped that a reconnaissance on the basis of the program as outlined, in which in fact the response of the North Sea to a suitably selected system of windfields is investigated, will enable to select a limited number of cases for a closer inspection.

For that purpose the basic equations with non-linear resistance will have to be used. It is hoped that from the research into the integration of the linearized equations suggestions will emerge which may facilitate the search for a suitable integration method for the more complicated equations.

In conjunction with the general solution several special pro.. blems also want clearing up. One of these is the examination of free oscillations in the North Sea as a whole and parts of it. Another is the condition at the open boundaries and also the interactions with bays and inlets. It will also be useful to analyse the combined motion under the influence of tide and windshear, because it might simplify the problem if they could be treated separately with the introduction of suitable correction terms.

Aside from the purely mathematical approach, it might also be tried to investigate the problems in a model, or to use a model, or models, in combination with mathematical methods. A hydraulic as well as an electrical analogy model could be designed to represent the dynamic behaviour of the North Sea.

The main difficulty in obtaining a true representation in a hydraulic model will be encountered in the realization of the Coriolis effect. This will require a hydraulic model of the North Sea as a whole to be constructed on a rotating platform.

In an electrical model the North Sea will have to be divided gridwise into a network of sections, with suitable connections lengthwise as well as cross-wise. The Coriolis effect will have to be represented by an additional system of connections.

Both these possibilities are being studied.

Though along several of the lines of this comprehensive sketch important work had been achieved already before February 1953, and on more the investigation is being pushed as strongly as possibly, it is still much too early to try to present more then an outline of the program. Many difficulties lie ahead, probably more than we can realize at this date. We are feeling however, in fact we have been made painfully aware, that we can no longer afford to live next door to and in a measure in and even under a sea, of which the dynamics are only imperfectly understood. It may take some time, and certainly not a little energy, but we are determined to wrest from the North Sea by our combined exertions and, we trust, the help of our neighbours around the North Sea, its mysteries, just as we have wrested from it a substantial part of our country. 
RESUME

LE PROGRAMME DES ETUDES SUR LES MARÉES DE TTMPETE DE LA MER DU NORD DANS LES PAYS BAS.

$$
\text { J.B. Schijf }
$$

La Wier du Word, étant peu profonde, est très susceptible à l'action du vent. Les tempêtes les plus violentes viennent du Nord Ouest en majorité, donnant des surélévations du plan a'eau dans le coin Sud.Est. Depuis des temps préhistoriques des tempêtes d'une sévérité exceptionnelle ont été accompagnés par des inondations des régions cotières basses des pays Bas et du pays voisins.

L'urgence vitale des études sur les marées de tempête s'est présentée très forciblement dans la nuit désastreuse du 31 janvier au 1 février 1953.

Sous la direction d'une Commission Spéciale, la Commission du Delta, une collaboration a été organisée dans ce but entre le Rijkswaterstaat, l'Institut Royal Mérlandais de la Météorologie et le Centre Mathématique.

Les investigations sont divisées en études statistiques et études dynamiques, étant poursuivi en conjonction. Les caractères généraux de ces études et les programmes envisagés sont esquissés. 